\title{
Attitude Control of a Six-legged Robot in Consideration of Actuator Dynamics by Optimal Servo Control System
}

\author{
H. Uchida* and K. Nonami† \\ *Kisarazu National College of Technology , †Chiba University
}

Japan

\section{Introduction}

There are more than 100 million land mines buried throughout the world, and, at present, the removal of these mines is primarily being done by hand. Our research group has suggested a mine detection method using six-legged robots, such as COMET-I, II, and III, to establish the land mine detection and removal technology. Mine detection by six-legged robots such as COMET-II and III have two manipulators at the front of the body designed for mine detection. Since most mine detection is performed on irregular terrain, it is necessary for a six-legged robot to maintain a stable posture in the mine detection using two manipulators. The authors have examined attitude control methods for achieving stable land mine detection by six-legged robot. With respect to the attitude control, we have examined the control method to control the height of the body and the pitching and the rolling angles according to the force reference signal in the perpendicular direction at the supporting leg. As an attitude control method, we have applied the extended sky hook suspension control (ESHSC) (Uchida \& Nonami, 2001), the optimal servo control system (Uchida \& Nonami, 2002), and the sliding mode control (Uchida \& Nonami, 2003). These methods targeted COMET-II, each leg link of which is driven by a direct current motor. However, at present, the research is conducted using COMET-III, in an attempt to develop it for practical use. Leg links of the COMET-III are driven by hydraulic actuators. When the above-mentioned attitude control methods are applied to COMET-III, it is difficult to realize stable attitude control because of the delay of the hydraulic actuators. Therefore, it is desirable to establish an attitude control method considering the delay of the actuator.

in In the present study, as a model considering the delay of the hydraulic actuator, we construct a mathematical model in which inputs are the driving torque of the thigh links in the supporting legs and the outputs are the height of the body, the pitching angle, and the rolling angle. The optimal servo control system in modern control theory is designed for this model. The validity of the proposed control method is verified by simulations performed using a 3D model of the COMET-III, in which the delay of the hydraulic actuator is modeled.

Source: Climbing \& Walking Robots, Towards New Applications, Book edited by Houxiang Zhang, ISBN 978-3-902613-16-5, pp.546, October 2007, Itech Education and Publishing, Vienna, Austria 


\section{Mine Detecting Six-legged Robot (COMET-III) and CAD Model}

Figure 1 shows the COMET-III mine detecting six-legged robot, which was developed at Chiba University. Figure 2 shows a 3D CAD model of COMET-III generated using mechanical analysis software. One leg of the robot has three degrees of freedom, and each joint is driven by a hydraulic actuator. The ankle of the leg has two degrees of freedom so that the sole of the entire bottom surface of the foot touches the ground. The parameters of COMET-III are shown in Table 1. The mass of the robot is approximately 1,200 [kgf]. The width of the body is 2,500 [mm], and the length of the body is 3,500 [mm]. The height of the body is 850 [mm]. An attitude sensor is attached to the body of COMET-III to detect the pitching and rolling angles. In addition, a six-axis force sensor is attached to each leg. In the present study, we verify the validity of the proposed attitude control method using a 3D model.

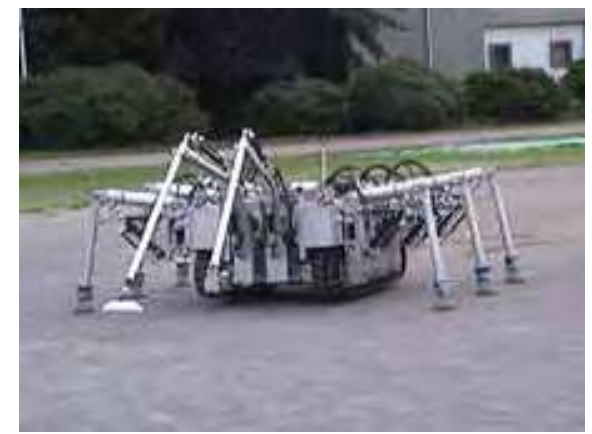

Fig. 1. COMET-III mine detecting six-legged robot

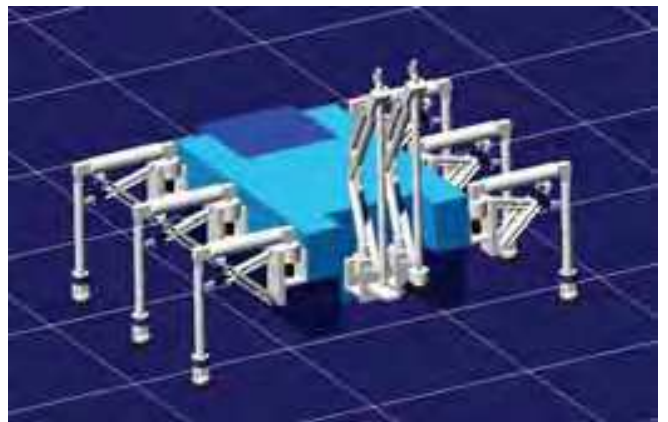

Fig. 2. 3D CAD model of COMET-III

\begin{tabular}{|c|c|}
\hline Weight & $1,200[\mathrm{kgf}]$ \\
\hline Width of the body & $2,500[\mathrm{~mm}]$ \\
\hline Length of the body & $3,500[\mathrm{~mm}]$ \\
\hline Height of the body & $850[\mathrm{~mm}]$ \\
\hline
\end{tabular}

Table 1. Parameters of COMET-III 


\section{Walking Pattern}

In the present study, it is desirable that there be little risk of the robot falling down, so that the attitude control method is examined. Therefore, static walking, which has high stability, is adopted. The effectiveness of the proposed method is verified by the walking pattern of five supporting legs. The leg numbers of a six-legged robot are shown in Figure 3. Figure 4 shows the walking pattern by five supporting legs. The period of the swing phase is 3 [s], and one period of the gait is 18 [s]. In Figure 4, the white area indicates a swing phase, and the black area indicates a supporting phase. Therefore, the order of the swing motion of the legs is $\mathrm{II} \rightarrow \mathrm{III} \rightarrow \mathrm{IV} \rightarrow \mathrm{I} \rightarrow \mathrm{IV} \rightarrow \mathrm{V}$.

Fig. 3. Leg numbers
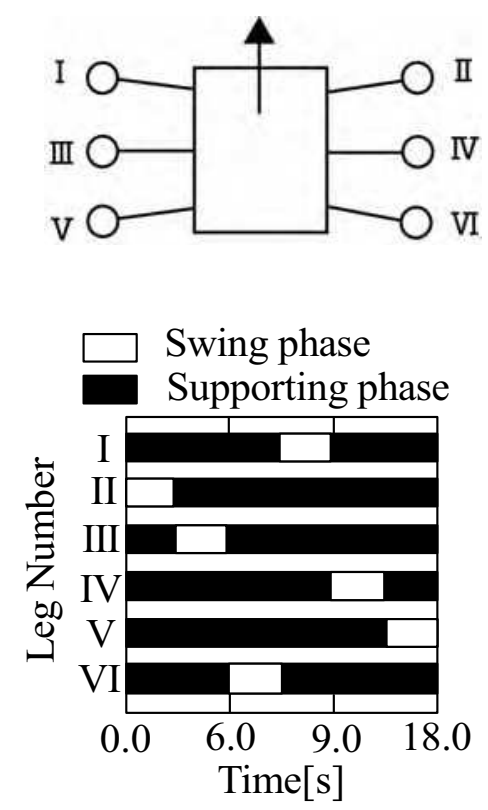

Fig. 4. Walking pattern

\section{Attitude Control Method}

This chapter examines the attitude control method that must be applied in the case of walking and mine detection work on irregular terrain such as a minefield. On even terrain, each angle of the joint is controlled to follow desired values, which are obtained by inversekinematics. However, on irregular terrain, it is difficult for only position control to keep the walking and attitude stable. Therefore, it is necessary for the attitude control to recover the body inclines by adding a force to the supporting legs. This attitude control is realized by controlling the force in the perpendicular direction of each supporting leg. Moreover, it is necessary to consider the delay of the hydraulic actuator because the hydraulic actuator is used for COMET-III.

In the present study, as a model considering the delay of the hydraulic actuator, we make a mathematical model in which the inputs are the driving torque of the thigh link in the 
supporting legs and the outputs are the height of the body, the pitching angle, and the rolling angle. In this process, we must seek the force acting the supporting legs, so that the force is obtained by an approximation formula using the angle and the angular velocity of the thigh link and the virtual spring and dumping coefficient. The delay of the hydraulic actuator is considered because this model calculates the force and the attitude in the perpendicular direction of the supporting leg from the state value of the thigh link. The optimal servo control system in modern control theory is designed for this model.

\subsection{Mathematical Model of the Thigh Link}

The leg links of the six-legged robot used in this research have three degrees of freedom, namely, the shoulder $\left(\theta_{1 i}\right)$, the thigh $\left(\theta_{2 i}\right)$, and the shank $\left(\theta_{3 i}\right)(i=1, \cdots, 6)$. Equation (1) shows the transfer function of the thigh link, which is very important in the case of the attitude control of COMET-III. The delay model of the hydraulic actuator is approximated

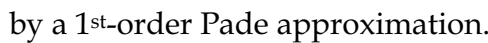

$$
G(s)=\frac{\alpha \omega_{n}{ }^{2}}{s^{2}+2 \zeta \omega_{n}+\omega_{n}{ }^{2}} \cdot \frac{1-\frac{1}{2} s T}{1+\frac{1}{2} s T}
$$

Figure 5 shows the step reference response of the PD feedback control system for the system shown as Eq. (1). A delay of approximately 0.2 [s] occurs.

The description of the state space in Eq. (1) is as follows:

$$
\begin{gathered}
\dot{x}_{i}=\left[\begin{array}{lll}
0 & 1 & 0 \\
0 & 0 & 1 \\
0 & a_{1} & a_{2}
\end{array}\right] x_{i}+\left[\begin{array}{l}
0 \\
0 \\
1
\end{array}\right] u_{i}(t) \\
\theta_{2 i}=\left[\begin{array}{lll}
c_{1} & c_{2} & 0
\end{array}\right]\left[\begin{array}{l}
x_{i 1} \\
x_{i 2} \\
x_{i 3}
\end{array}\right], \quad(i=1, \cdots, 6)
\end{gathered}
$$

where

$$
\begin{array}{ll}
x_{i}: \text { state variable vector } & u_{i} \text { : input vector } \\
\theta_{2 i}: \text { angle of each thigh } & i: \text { foot number }
\end{array}
$$

$a_{1}, a_{2}, c_{1}, c_{2}$ : coefficients obtained by Eq. (1). 


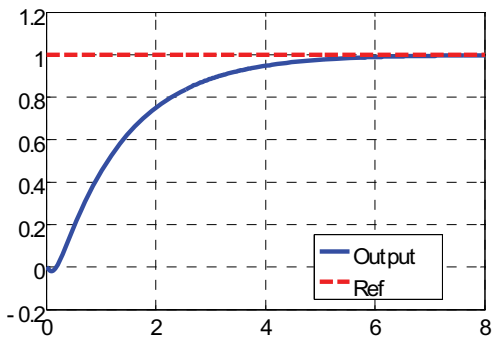

Fig. 5. Step response of the thigh driven by the hydraulic cylinder

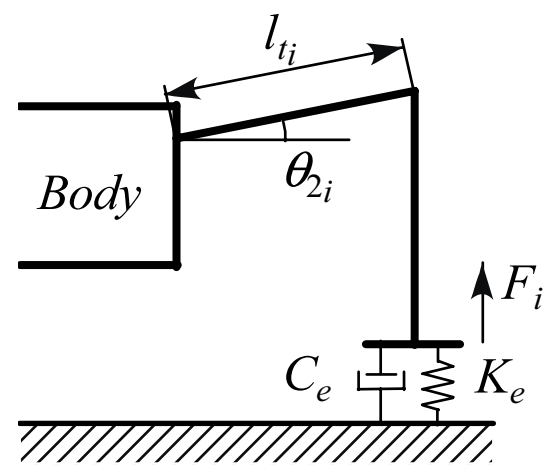

Fig. 6. Relationship between the angle of thigh and the force in the perpendicular direction of the supporting leg.

\subsection{Mathematical Model from the Input of the Thigh Link to the Attitude of the Body} Figure 6 shows the relationship between the angle of the thigh and the force in the perpendicular direction of the supporting leg. In Fig. $6, l_{t i}$ is the length of the thigh, and $C_{e}$ and $K_{e}$ are the dumping and the spring coefficient of the ground, respectively. The following assumptions are used in Fig. 6.

(1) The shank always becomes vertical to the ground $\left(\theta_{3 i}=0\right)$.

(2) The change of $\theta_{2 i}$ is small.

According to the above assumptions, the force $F_{i}$ in the perpendicular direction of the supporting leg is given by the following equation:

$$
F_{i}=l_{t i} K_{e} \theta_{2 i}+l_{t i} C_{e} \dot{\theta}_{2 i}
$$

Substituting Eq. (2) for Eq. (3), $F_{i}$ is given by the following equation:

$$
F_{i}=l_{t i} K_{e} c_{1 i} x_{21 i}+l_{t i}\left(K_{e} c_{2 i}+C_{e} c_{1 i}\right) x_{22 i}+l_{t i} C_{e} c_{2 i} x_{23 i}
$$


Moreover, the height, and the pitching and rolling angles of the body are controlled by controlling the force in the perpendicular direction of the supporting leg. The motion equations of the force and the moment equilibrium in the perpendicular direction and the pitching and rolling axes in the case of support by six legs are given by Eq. (5). Figure 7 shows the coordinates of each foot.

$$
\left\{\begin{array}{c}
M \ddot{z}=F_{1}+F_{2}+F_{3}+F_{4}+F_{5}+F_{6}-M g \\
I_{p} \ddot{\theta}_{p}=y_{1} F_{1}+y_{2} F_{2}+y_{3} F_{3}+y_{4} F_{4}+y_{5} F_{5}+y_{6} F_{6} \\
I_{r} \ddot{\theta}_{r}=x_{1} F_{1}+x_{2} F_{2}+x_{3} F_{3}+x_{4} F_{4}+x_{5} F_{5}+x_{6} F
\end{array}\right\}
$$

where

$$
\begin{array}{ll}
M: \text { mass of the body } & g: \text { acceleration of gravity } \\
I_{p} \text { : inertia around the pitching axis } & I_{r}: \text { inertia around the rolling axis }
\end{array}
$$

Substituting Eq. (4) for Eq. (5), and by defining the $24^{\text {th-order }}$ state value as $x=\left[x_{11}, x_{21}, x_{31}, x_{12}, \cdots, x_{36}, \theta_{p}, \theta_{r}, z, \dot{\theta}_{p}, \dot{\theta}_{r}, \dot{z}\right]^{T}$, which consists of the state values of each thigh link, the pitching and rolling angles, the height of the body and its velocity, the following state equation is obtained:

$$
\left[\begin{array}{c}
\dot{x}_{1} \\
\dot{x}_{2} \\
\dot{x}_{3} \\
\dot{x}_{4} \\
\dot{x}_{5} \\
\dot{x}_{6} \\
\dot{x}_{7} \\
\dot{x}_{8}
\end{array}\right]=\left[\begin{array}{cccccccc}
A_{11} & 0_{3 \times 3} & 0_{3 \times 3} & 0_{3 \times 3} & 0_{3 \times 3} & 0_{3 \times 3} & 0_{3 \times 3} & 0_{3 \times 3} \\
0_{3 \times 3} & A_{22} & 0_{3 \times 3} & 0_{3 \times 3} & 0_{3 \times 3} & 0_{3 \times 3} & 0_{3 \times 3} & 0_{3 \times 3} \\
0_{3 \times 3} & 0_{3 \times 3} & A_{33} & 0_{3 \times 3} & 0_{3 \times 3} & 0_{3 \times 3} & 0_{3 \times 3} & 0_{3 \times 3} \\
0_{3 \times 3} & 0_{3 \times 3} & 0_{3 \times 3} & A_{44} & 0_{3 \times 3} & 0_{3 \times 3} & 0_{3 \times 3} & 0_{3 \times 3} \\
0_{3 \times 3} & 0_{3 \times 3} & 0_{3 \times 3} & 0_{3 \times 3} & A_{55} & 0_{3 \times 3} & 0_{3 \times 3} & 0_{3 \times 3} \\
0_{3 \times 3} & 0_{3 \times 3} & 0_{3 \times 3} & 0_{3 \times 3} & 0_{3 \times 3} & A_{66} & 0_{3 \times 3} & 0_{3 \times 3} \\
0_{3 \times 3} & 0_{3 \times 3} & 0_{3 \times 3} & 0_{3 \times 3} & 0_{3 \times 3} & 0_{3 \times 3} & 0_{3 \times 3} & A_{78} \\
A_{81} & A_{82} & A_{83} & A_{84} & A_{85} & A_{86} & 0_{3 \times 3} & 0_{3 \times 3}
\end{array}\right]\left[\begin{array}{c}
x_{1} \\
x_{2} \\
x_{3} \\
x_{4} \\
x_{5} \\
x_{6} \\
x_{7} \\
x_{8}
\end{array}\right]+
$$




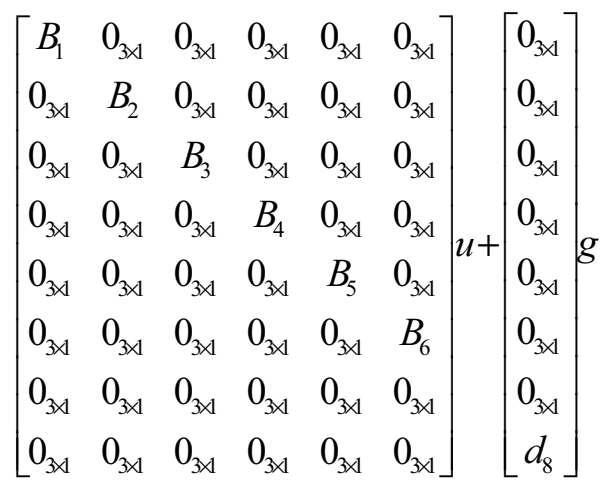

where,

$$
\begin{gathered}
x_{i}=\left[\begin{array}{l}
x_{1 i} \\
x_{2 i} \\
x_{3 i}
\end{array}\right](i=1 \sim 6), \quad x_{7}=\left[\begin{array}{c}
z \\
\theta_{p} \\
\theta_{r}
\end{array}\right], \quad x_{8}=\left[\begin{array}{c}
\dot{z} \\
\dot{\theta}_{p} \\
\dot{\theta}_{r}
\end{array}\right], \\
A_{i i}=\left[\begin{array}{lll}
0 & 1 & 0 \\
0 & 0 & 1 \\
0 & a_{1} & a_{2}
\end{array}\right](i=1, \cdots, 6), \quad A_{78}=\left[\begin{array}{lll}
1 & 0 & 0 \\
0 & 1 & 0 \\
0 & 0 & 1
\end{array}\right], \\
A_{8 i}=\left[\begin{array}{ccc}
\frac{K_{e} l c_{1}}{M} & \frac{K_{e} l c_{2}+C_{e} l c_{1}}{M} & \frac{C_{e} l c_{1}}{M} \\
\frac{K_{e} l c_{1}}{I_{p}} y_{i} & \frac{K_{e} l c_{2}+C_{e} l c_{1}}{I_{p}} y_{i} & \frac{C_{e} l c_{1}}{I_{p}} y_{i} \\
\frac{K_{e} l c_{1}}{I_{r}} x_{i} & \frac{K_{e} l c_{2}+C_{e} l c_{1}}{I_{r}} x_{i} & \frac{C_{e} l c_{1}}{I_{r}} x_{i}
\end{array}\right](i=1, \cdots, 6), \\
B_{i}=\left[\begin{array}{l}
0 \\
0 \\
1
\end{array}\right]\left(\begin{array}{l}
u_{1} \\
u_{2} \\
u_{3} \\
u_{4} \\
u_{5} \\
u_{6}
\end{array}\right], \\
\left.i_{1}, \cdots, 6\right), \quad\left[\begin{array}{l}
1 \\
0 \\
0
\end{array}\right]
\end{gathered}
$$


Equation (6) is rewritten as follows:

$$
\dot{x}=A x+B u+f g
$$

Here, each row shows the following:

$$
\begin{aligned}
& 1^{\text {st } \cdots 3^{\text {rd }}}: 1^{\text {st } \cdots} 3^{\text {rd }} \text { column is Eq. (2) and shows the dynamics of Leg I. } \\
& 4^{\text {th } \cdots 6^{\text {th }}} \quad: 4^{\text {th } \cdots} 6^{\text {th }} \text { column is Eq. (2) and shows the dynamics of Leg II. } \\
& 7^{\text {th }} \cdot 9^{\text {th }} \quad: 7^{\text {th }} \cdot 9^{\text {th }} \text { column is Eq. (2) and shows the dynamics of Leg III. } \\
& 10^{\text {th }} \cdots 12^{\text {th }} \quad: 10^{\text {th } \cdots 12^{\text {th }}} \text { column is Eq. (2) and shows the dynamics of Leg IV. } \\
& 13^{\text {th }} \cdots 1^{\text {th }} \quad: 13^{\text {th }} \cdots 15^{\text {th }} \text { column is Eq. (2) and shows the dynamics of Leg V. } \\
& 16^{\text {th } \cdots} 18^{\text {th }}: 16^{\text {th }} \cdots 18^{\text {th }} \text { column is Eq. (2) and shows the dynamics of Leg IV. } \\
& 19^{\text {th }} \cdots 21^{\text {st }} \quad \text { : shows the relationship among the angular velocity } \dot{\theta}_{p}, \dot{\theta}_{r} \text {, and } \dot{z} \text {. } \\
& 22^{\text {nd }} \cdot 24^{\text {th }} \quad \text { : shows the equation of motion in Eq. (5). }
\end{aligned}
$$

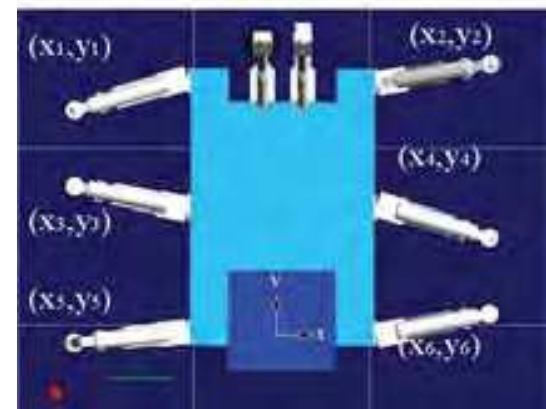

Fig. 7. Coordinates of each leg

\subsection{Optimal Servo System}

The servo system that the system shown by Eq. (7) follows to the desired value is designed.

$$
\left\{\begin{array}{l}
\dot{z}=r-c x \\
\dot{x}=A x+B u+f g
\end{array}\right.
$$

where, $\dot{z}$ is the error vector between the desired vector and the output vector. Equation (8) is given in matrix form as follows:

$$
\left[\begin{array}{c}
\dot{z} \\
\dot{x}
\end{array}\right]=\left[\begin{array}{cc}
0 & -c \\
0 & A
\end{array}\right]\left[\begin{array}{l}
z \\
x
\end{array}\right]+\left[\begin{array}{l}
0 \\
B
\end{array}\right] u+\left[\begin{array}{l}
0 \\
d
\end{array}\right] g+\left[\begin{array}{l}
I \\
0
\end{array}\right] r
$$

Equation (9) is described in equation form as follows: 


$$
\dot{x}_{g}=A_{g} x_{g}+B_{g} u+d_{g} g+f_{g} r
$$

The feedback (FB) control input $u_{b}$ to the actuator driving the thigh link is obtained in order to minimize the following cost function:

$$
J=\int_{0}^{\infty}\left[x_{g}(t)^{T} Q x_{g}(t)+u(t)^{T} R u(t)\right] d t
$$

where $Q(n \times n)$ and $R(m \times m)$ are the weighting matrixes given by the design specifications, and $Q \geq 0, R>0$. The control input to minimize Eq. (11) is as follows:

$$
u_{b}^{o}=-R^{-1} B_{g}^{T} P x
$$

where $P(n \times n)$ is the solution of the following Ricatti equation:

$$
P A_{g}+A_{g}^{T} P-P B_{g} R^{-1} B_{g}^{T} P+Q=0
$$

Figure 8 shows a block diagram of the optimal servo control system.

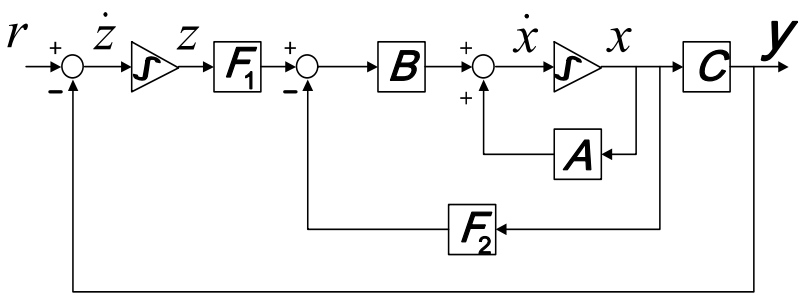

Fig. 8. Block diagram of optimal servo control system

\subsection{Making a Controlled System for an Uncontrolled System}

We examined the controllability for the system as Eq. (10), which is constructed using Eq. (2). However, it has become an uncontrollable system. The $3^{\text {rd }}$-order delay system is then approximated to the delay system of the $2^{\text {nd }}$-order model, which is given by following equation:

$$
G(s)=\frac{\omega_{n}{ }^{2}}{s^{2}+2 \zeta \omega_{n} s+\omega_{n}{ }^{2}}
$$


In order to obtain the same results for the $3^{\text {rd }}$-order model as were obtained for the $2^{\text {nd }}$-order model, both the values of the magnitude and the phase in the Bode diagram coincide with the angular velocity of the walking speed. We searched the values $\omega_{n}$ and $\zeta$ to satisfy the above condition and obtained the results of $\omega_{n}=9[\mathrm{rad} / \mathrm{s}]$ and $\zeta=0.9$. Figure 9 shows a comparison of the bode plot for the $2^{\text {nd }}$-order system and the $3^{\text {rd }}$-order system. In Fig. 9, the solid line shows the $2^{\text {nd }}$-order model, and the dashed line shows the $3^{\text {rd }}$-order model. The solid line drawn around $0.6[\mathrm{rad} / \mathrm{s}]$ at the angular velocity in the figure shows the angular velocity of the walking in this research. The difference between the systems is significant in the high-frequency range. However, in this study, in the bandwidth of the walking speed, the magnitude and the phase coincide. Therefore, we consider this approximation to be appropriate, and so the attitude control method is designed to replace Eq. (2) with Eq. (14), and the effectiveness is verified. The system described by Eq. (7) becomes the $19^{\text {th-order }}$ model.

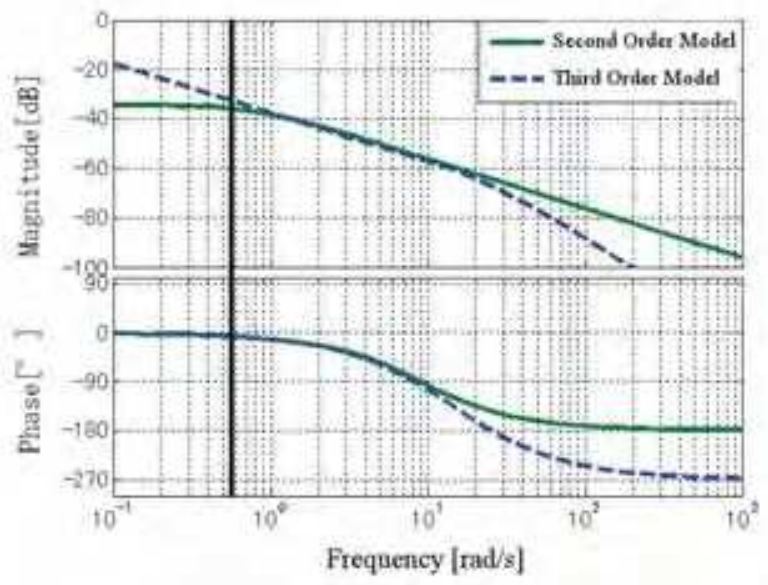

Fig. 9. Comparison of bode plots for the $2^{\text {nd }}$-order system and the $3^{\text {rd }}$-order system

\section{3D Simulation}

In this section, in order to verify the validity of the attitude control method considering the delay of the hydraulic actuator, we examine the walking characteristics on even terrain and on irregular terrain using the 3D model of the COMET-III six-legged robot. We then discuss the performance of the attitude control method considering the delay by the simulation results. The shoulder and shank parts of the leg links are controlled by the PD control, which is a very popular control method to follow the desired value $\theta_{1 \text { ir }}$ and $\theta_{3 i r}$ (ir $=1,2, \cdots, 6)$ obtained by solving inverse-kinematics. In addition, in the case of walking with five supporting legs, the attitude control is applied for the five supporting legs, except for one swinging leg. The swinging leg is controlled by the PD control. 


\subsection{Walking on Even Terrain}

Figure 10 shows the 3D simulation results of the proposed attitude control method on even terrain. Figures 10(a), 10(b), and 10(c) show the time response of the pitching angle, the rolling angle, and the height of the body, respectively. The variation of the attitude is very small, and the attitude control works to recover the variation. The six-legged robot can realize a stable walk.

(a) Pitching angle
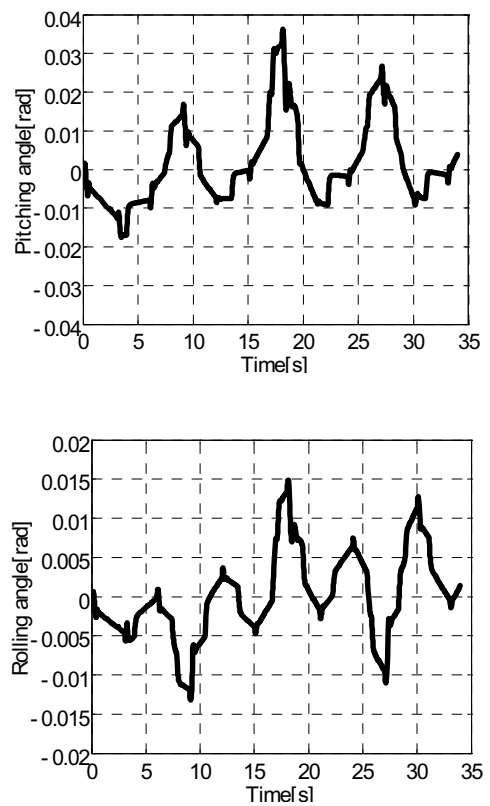

(b) Rolling angle

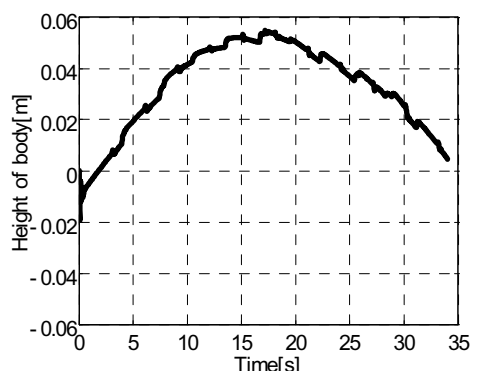

(c) Height of the body

Fig. 10. Simulation results in the case of even terrain

\subsection{Walking on Irregular Terrain}

Figure 11 shows the simulation case for irregular terrain, in which the six-legged robot walks over a $10[\mathrm{~cm}]$ high step. The six-legged robot starts to climb the step at $3[\mathrm{~s}]$ and leaves the step at 54 [s]. Figure 12 shows the 3D simulation results for irregular terrain. 
Figures 12(a), 12(b), and 12(c) show the time response of the pitching angle, the rolling angle, and the height of the body, respectively. The vibrations occur in the pitching and rolling angles. In addition, approximately 40 [s] is required to settle down at the height of the body of approximately $0[\mathrm{~m}]$. However, the influence of the step is slight and the six-legged robot can realize a stable walk. Moreover, Fig. 13 shows the animation results of the 3D simulation on irregular terrain. Figures 13(a), 13(b), and 13(c) show animations at the times of 3.45 [s], 70.8 [s], and 136.25 [s], respectively. In Fig. 13(c), two manipulator attached to the front part of the body are pushed into the ground. However, this causes no particular problem, because it does not influence the walking operation. Based on the above-mentioned results, the attitude control method that considers the dynamics of the actuator proposed in the present study is effective.

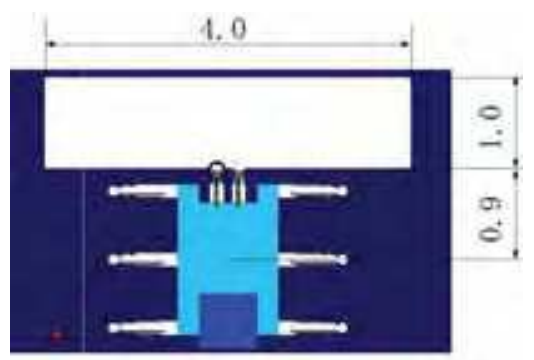

Fig. 11. Case of walking on uneven terrain

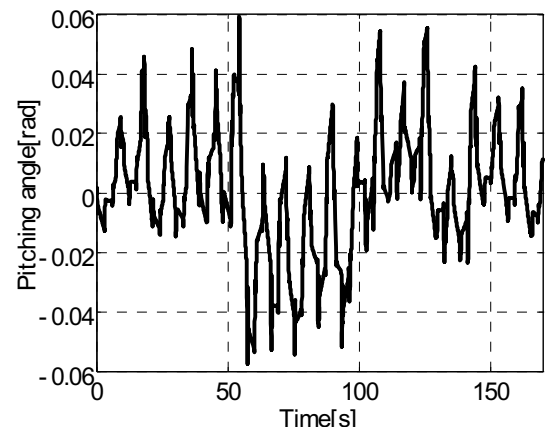

(a) Pitching angle

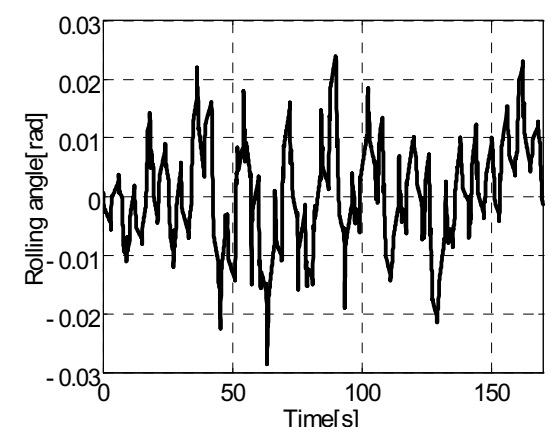

(b) Rolling angle 
(c) Height of the body

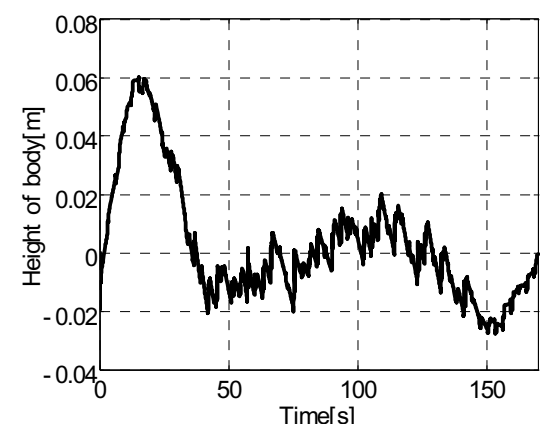

Fig. 12. Simulation results in the case of irregular terrain

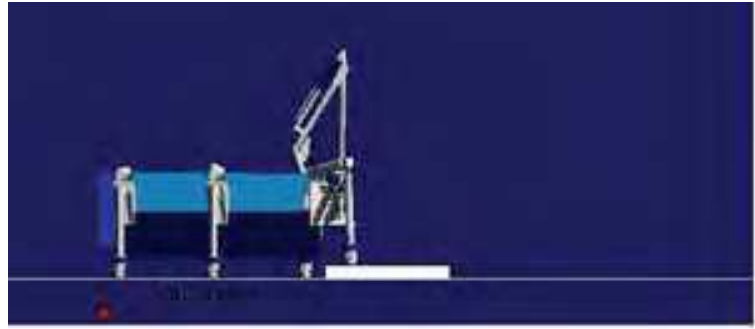

(a) Simulation time: 3.45 [s]

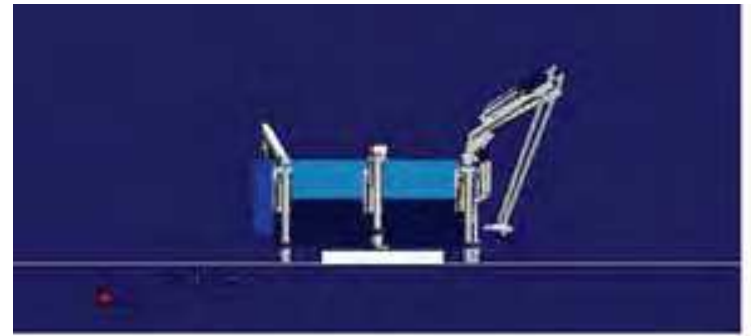

(b) Simulation time: $70.8[\mathrm{~s}]$

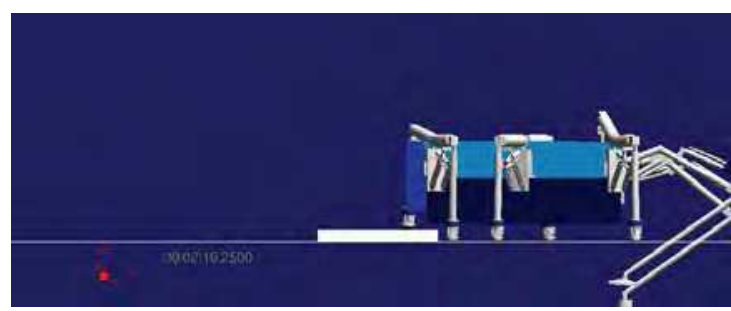

(c) Simulation time: 136.25 [s]

Fig. 13. Animations of walking on uneven terrain 


\section{Conclusion}

In the present study, we examined the attitude control method considering the delay of the hydraulic actuator whereby the mine detection six-legged robot can realize stable walking on irregular terrain without to make an orbit of the foot for irregular terrain. The following results were obtained.

(1) As an attitude control method considering the delay of the actuator of the thigh links, we derive a mathematical model in which the inputs are the driving torque of the thigh links in the supporting legs and the outputs are the height of the body, the pitching angle, and the rolling angle.

(2) The $3^{\text {rd }}$-order delay system is approximated as a $2^{\text {nd }}$-order delay system, and an optimal servo control system is applied as the attitude control method.

(3) The validity of the proposed attitude control method is discussed based on 3D simulations of walking on even terrain and irregular terrain.

The effectiveness of the proposed control method will be examined experimentally in the future. Moreover, the method by which to improve the transition response with the time delay system will be examined.

\section{References}

Uchida, H. \& Nonami, K. (2001), Quasi force control of mine detection six-legged robot COMET-I using attitude sensor, Proceeding of $4^{\text {th }}$ International Conference on Climbing and Walking Robots, pp 979-988, ISBN 186058365 2, Karlsruhe, Germany, September, 2001, Professional Engineering Publishing, London.

Uchida, H. \& Nonami, K. (2002), Attitude Control of Six-Legged Robot Using Optimal Control Theory, Proceeding of $6^{\text {th }}$ International Conference on Motion and Vibration Control, pp 391-396, Saitama, Japan, August, 2002, The Dynamics, Measurement and Control Division of Japan Society of Mechanical Engineers, Tokyo.

Uchida, H. \& Nonami, K. (2003), Attitude control of six-legged robot using sliding mode control, Proceeding of $6^{\text {th }}$ International Conference on Climbing and Walking Robots, pp 103-110, ISBN 186058409 8, Catania, Italy, September, 2003, Professional Engineering Publishing, London. 


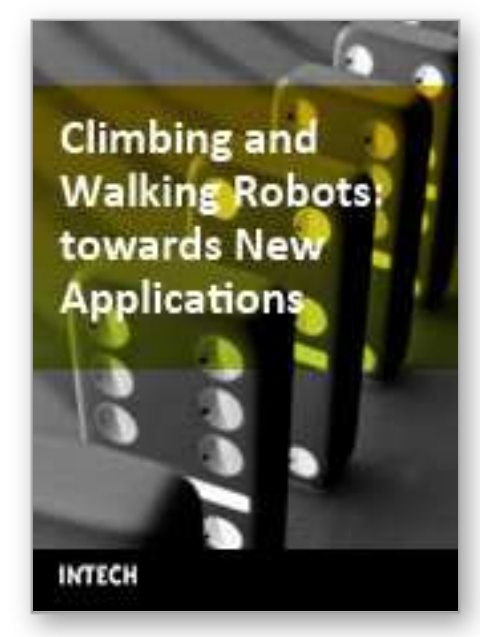

\author{
Climbing and Walking Robots: towards New Applications \\ Edited by Houxiang Zhang
}

ISBN 978-3-902613-16-5

Hard cover, 546 pages

Publisher I-Tech Education and Publishing

Published online 01, October, 2007

Published in print edition October, 2007

With the advancement of technology, new exciting approaches enable us to render mobile robotic systems more versatile, robust and cost-efficient. Some researchers combine climbing and walking techniques with a modular approach, a reconfigurable approach, or a swarm approach to realize novel prototypes as flexible mobile robotic platforms featuring all necessary locomotion capabilities. The purpose of this book is to provide an overview of the latest wide-range achievements in climbing and walking robotic technology to researchers, scientists, and engineers throughout the world. Different aspects including control simulation, locomotion realization, methodology, and system integration are presented from the scientific and from the technical point of view. This book consists of two main parts, one dealing with walking robots, the second with climbing robots. The content is also grouped by theoretical research and applicative realization. Every chapter offers a considerable amount of interesting and useful information.

\title{
How to reference
}

In order to correctly reference this scholarly work, feel free to copy and paste the following:

H. Uchida and K. Nonami (2007). Attitude Control of a Six-Legged Robot in Consideration of Actuator Dynamics by Optimal Servo Control System, Climbing and Walking Robots: towards New Applications, Houxiang Zhang (Ed.), ISBN: 978-3-902613-16-5, InTech, Available from:

http://www.intechopen.com/books/climbing_and_walking_robots_towards_new_applications/attitude_control_o f_a_six-legged_robot_in_consideration_of_actuator_dynamics_by_optimal_servo_contro

\section{INTECH}

open science | open minds

\author{
InTech Europe \\ University Campus STeP Ri \\ Slavka Krautzeka 83/A \\ 51000 Rijeka, Croatia \\ Phone: +385 (51) 770447 \\ Fax: +385 (51) 686166 \\ www.intechopen.com
}

\author{
InTech China \\ Unit 405, Office Block, Hotel Equatorial Shanghai \\ No.65, Yan An Road (West), Shanghai, 200040, China \\ 中国上海市延安西路65号上海国际贵都大饭店办公楼 405 单元 \\ Phone: +86-21-62489820 \\ Fax: +86-21-62489821
}


(C) 2007 The Author(s). Licensee IntechOpen. This chapter is distributed under the terms of the Creative Commons Attribution-NonCommercial-ShareAlike-3.0 License, which permits use, distribution and reproduction for non-commercial purposes, provided the original is properly cited and derivative works building on this content are distributed under the same license. 